\title{
Article \\ GSK-3 $\alpha$ Inhibition in Drug-Resistant CML Cells Promotes Susceptibility to NK Cell-Mediated Lysis in an NKG2D- and NKp30-Dependent Manner
}

\author{
Nayoung Kim ${ }^{1,2,+}$, , Mi Yeon Kim ${ }^{3,+}$, Woo Seon Choi ${ }^{3,4,+}$, Eunbi $\mathrm{Yi}^{3}$, Hyo Jung Lee ${ }^{3 \oplus}$ and Hun Sik Kim ${ }^{3,4, *}$ \\ 1 Department of Convergence Medicine, University of Ulsan College of Medicine, Seoul 05505, Korea; \\ naykim@amc.seoul.kr \\ 2 Asan Institute for Life Sciences, Asan Medical Center, University of Ulsan College of Medicine, \\ Seoul 05505, Korea \\ 3 Department of Biomedical Sciences, Microbiology, University of Ulsan College of Medicine, \\ Seoul 05505, Korea; sunkimnkt@daum.net (M.Y.K.); doloref@naver.com (W.S.C.); \\ rainyis0603@gmail.com (E.Y.); gywjddl231@hanmail.net (H.J.L.) \\ 4 Stem Cell Immunomodulation Research Center (SCIRC), Asan Medical Center, \\ University of Ulsan College of Medicine, Seoul 05505, Korea \\ * Correspondence: hunkim@amc.seoul.kr; Tel.: +82-2-3010-2207 \\ + These authors contributed equally to this work.
}

check for updates

Citation: Kim, N.; Kim, M.Y.; Choi, W.S.; Yi, E.; Lee, H.J.; Kim, H.S. GSK-3 $\alpha$ Inhibition in Drug-Resistant CML Cells Promotes Susceptibility to NK Cell-Mediated Lysis in an NKG2D- and NKp30-Dependent Manner. Cancers 2021, 13, 1802. https://doi.org/10.3390/ cancers 13081802

Academic Editor: Cristina Bottino

Received: 9 February 2021

Accepted: 8 April 2021

Published: 9 April 2021

Publisher's Note: MDPI stays neutral with regard to jurisdictional claims in published maps and institutional affiliations.

Copyright: (c) 2021 by the authors. Licensee MDPI, Basel, Switzerland This article is an open access article distributed under the terms and conditions of the Creative Commons Attribution (CC BY) license (https:// creativecommons.org/licenses/by/ $4.0 /)$.
Simple Summary: Glycogen synthase kinase-3 (GSK-3) is a serine/threonine protein kinase that has gained considerable interest as a therapeutic target for cancer due to its key involvement in growth arrest and apoptosis of tumor cells. Moreover, GSK-3, especially GSK-3 $\beta$, limits the activation of NK cells, key innate effectors in cancer immunosurveillance, triggered by diverse activating receptors. However, the role of GSK-3 in the regulation of activating ligands on target cells that confer susceptibility to NK cells remains unclear and is the aim of this study. Here, we provide evidence that GSK-3 $\alpha$ primarily restrains the expression of ligands for activating receptors such as NKG2D, NKp30 but not DNAM-1, thereby reducing target susceptibility to NK cells. Thus, our results suggest a distinct role of GSK-3 isoforms in target cells vs NK cells for regulating NK cell reactivity and GSK-3 $\alpha$ inhibition as a relevant strategy to enhance target susceptibility to NK cells.

Abstract: Natural killer (NK) cells are innate cytotoxic lymphocytes that provide early protection against cancer. NK cell cytotoxicity against cancer cells is triggered by multiple activating receptors that recognize specific ligands expressed on target cells. We previously demonstrated that glycogen synthase kinase (GSK)-3 $\beta$, but not GSK-3 $\alpha$, is a negative regulator of NK cell functions via diverse activating receptors, including NKG2D and NKp30. However, the role of GSK-3 isoforms in the regulation of specific ligands on target cells is poorly understood, which remains a challenge limiting GSK-3 targeting for NK cell-based therapy. Here, we demonstrate that GSK-3 $\alpha$ rather than GSK$3 \beta$ is the primary isoform restraining the expression of NKG2D ligands, particularly ULBP2/5/6, on tumor cells, thereby regulating their susceptibility to NK cells. GSK-3 $\alpha$ also regulated the expression of the NKp30 ligand B7-H6, but not the DNAM-1 ligands PVR or nectin-2. This regulation occurred independently of BCR-ABL1 mutation that confers tyrosine kinase inhibitor (TKI) resistance. Mechanistically, an increase in PI3K/Akt signaling in concert with c-Myc was required for ligand upregulation in response to GSK-3 $\alpha$ inhibition. Importantly, GSK-3 $\alpha$ inhibition improved cancer surveillance by human NK cells in vivo. Collectively, our results highlight the distinct role of GSK-3 isoforms in the regulation of NK cell reactivity against target cells and suggest that GSK$3 \alpha$ modulation could be used to enhance tumor cell susceptibility to NK cells in an NKG2D- and NKp30-dependent manner.

Keywords: natural killer cell; GSK-3 $\alpha$; NKG2D; NKp30; BCR-ABL1 


\section{Introduction}

Natural killer (NK) cells are cytotoxic innate lymphocytes and act as the first-line cellular barrier in cancer immunosurveillance [1-3]. NK cells rapidly kill a broad spectrum of tumor cells while sparing healthy cells through direct cytolysis and the production of cytokines (e.g., IFN- $\gamma$, TNF- $\alpha$ ), without prior sensitization. Unlike major histocompatibility complex (MHC)-restricted killing of tumor cells by cytotoxic T cells, NK cells rely on an array of innate activating and inhibitory receptors for tumor cell recognition and elimination. The activating receptors that trigger NK cell effector functions include NKG2D, DNAM-1, NKp30, NKp44, and NKp46, each of which has a unique ligand specificity. As key antitumor effector cells that do not cause graft-versus-host disease, NK cells are considered a safe off-the-shelf cellular therapeutic for cancer immunotherapy [4-6]. Accumulating evidence has shown NK cell-based immunotherapy to be efficacious in some cancers, particularly hematologic malignancies, but it is often associated with a transient clinical benefit and eventual disease progression in many clinical settings. This limited success highlights the need to develop rational therapeutic strategies to achieve enhanced and durable clinical responses with NK cell therapy.

Glycogen synthase kinase-3 (GSK-3) is a serine/threonine protein kinase that is ubiquitously expressed and regulates diverse cellular functions including glycogen metabolism, cell death, and immune responses [7-10]. GSK-3 has two isoforms, GSK-3 $\alpha$ (51 kDa) and GSK-3 $\beta(47 \mathrm{kDa})$, that are encoded by separate genes and differ significantly in the Nand C-terminal region [11]. Despite their redundancy in certain cellular functions [12], these isoforms also play non-overlapping roles, as demonstrated by distinct phenotypes in GSK-3 $\alpha$ - and GSK-3 $\beta$-deficient mice [13-16]. GSK-3 $\beta$ has the most substrates of any known kinase, with over 500 proposed substrates based on an in silico analysis [17] and approximately 100 confirmed substrates involved in key cellular pathways [18-20]. In this regard, GSK-3 has gained considerable attention as a promising therapeutic target in cancer therapy due to its central role in growth arrest and apoptosis of tumor cells and its specific targeting enabled by potent pharmacological inhibitors [19,21,22]. Accordingly, pharmacologic inhibition of GSK-3 leads to growth arrest or apoptosis in diverse leukemic cells [23-25]. Moreover, we previously demonstrated that GSK-3, especially GSK-3 $\beta$, negatively regulates NK cell activity triggered by diverse activating receptors, including NKG2D and NKp30 [26]. In support, pharmacologic inhibition or genetic knockdown of GSK-3 $\beta$ enhances NK cell functions against K562 cells, a human chronic myeloid leukemia $(\mathrm{CML})$ cell line. Similarly, pharmacologic or genetic inactivation of GSK-3 $\beta$ restores the cytotoxicity of NK cells against acute myeloid leukemia (AML) cells [27], suggesting the benefit of GSK-3 inhibition in leukemia treatment.

In addition, the expression of ligands for NK activating receptors is an important determinant of NK cell reactivity against cancer cells. To date, the role of GSK-3 in the regulation of activating ligands on leukemia cells remains unclear, given the results of a previous study that only used pharmacological agents for GSK-3 inhibition and only assessed the limited ligands (i.e., MICA/B and PVR/CD155) for NKG2D and DNAM-1 [28]. NKG2D recognizes MHC class I-like molecules, including ULBP1-6 as well as MICA/B, while the ligands for DNAM-1 are PVR/CD155 and nectin-2/CD112 [1,29,30]. In addition to these, NKp30 is a potent activating receptor that contributes to NK cell surveillance of leukemia cells and binds to B7-H6 on diverse tumor cells [31,32]. In this study, we sought to assess the role of GSK-3 isoforms in the NK cell susceptibility of CML cells that are sensitive or resistant to targeted therapy. Using both pharmacologic and genetic inactivation of GSK-3, we investigated the potential mechanisms through which GSK-3 isoforms regulate the expression of ligands for diverse NK cell activating receptors and whether such GSK-3 inhibition promotes the anti-leukemic activity of NK cells, including in a xenograft mouse model of leukemia clearance that relies on human NK cell activity. 


\section{Materials and Methods}

\subsection{Cells and Reagents}

Human primary samples were obtained from healthy donors after informed consent in accordance with protocols approved by the Institutional Review Board (IRB) of Asan Medical Center and the Declaration of Helsinki. Peripheral blood mononuclear cells (PBMCs) from healthy donors were isolated using lymphocyte separation medium (MP Biomedicals, Santa Ana, CA, USA). Human NK cells were isolated from PBMCs by negative selection with an NK cell isolation kit (StemCell Technologies, Vancouver, BC, Canada). Isolated cell populations were $97-99 \% \mathrm{CD}^{-} \mathrm{CD}^{+} 6^{+}$, as assessed by flow cytometry, and were expanded according to a protocol described below. PBMCs, purified NK cells, or expanded NK cells were used as effector cells for functional assays after $24 \mathrm{~h}$ of incubation with human recombinant IL-2 (rIL-2) (200 U/mL; Roche, Basel, Switzerland). The human CML blast crisis (BC) cell line KCL-22 was cultured in RPMI 1640 (Gibco/Thermo Fisher Scientific, Waltham, MA, USA) supplemented with 10\% FBS (Gibco). The human tyrosine kinase inhibitor (TKI)-resistant CML-BC cell line KCL-22M, which harbors the BCR-ABL1 point mutation T315I, was cultured in RPMI 1640 supplemented with $10 \%$ FBS and $2 \mu \mathrm{M}$ imatinib mesylate (IM) (Sigma-Aldrich, St. Louis, MO, USA). The presence of one $B C R-A B L 1$ allele containing the T315I mutation and one wild-type allele of the c- $A B L$ gene in the KCL-22M cell line was confirmed using PCR amplification and direct sequencing of genomic DNA, as previously described [33]. Thiadiazolidinone (TDZD-8), lithium chloride (LiCl), LY294002, and 10058-F4 were from Calbiochem (San Diego, CA, USA). The FarRed cell proliferation kit and CSFE cell proliferation kit were from Invitrogen/Thermo Fisher Scientific.

\subsection{NK Cell Expansion}

Primary human NK cells isolated from PBMCs were expanded as previously described [34], with some modifications. PBMCs $\left(1.5 \times 10^{6}\right.$ cells $)$ were incubated in a 24 -well tissue culture plate with 100 Gy-irradiated K562-mb15-41BBL cells $\left(1 \times 10^{6}\right.$ cells) in Stem Cell Growth medium (SCGM; CellGenix, Freiburg, Germany) supplemented with 10\% FBS and $10 \mathrm{U} / \mathrm{mL}$ rIL-2. The half volume of medium was exchanged every 2 days with fresh medium containing $10 \mathrm{U} / \mathrm{mL}$ rIL-2. After a week, residual T cells were depleted with a CD3 positive selection kit (StemCell Technologies. The remaining cells were incubated in SCGM supplemented with $10 \%$ FBS, 100 U/mL rIL-2, and 5 ng/mL rIL-15 (PeproTech, Rocky Hill, NJ, USA) for 2 additional weeks, with a half-medium exchange every 2 days. NK cell populations in PBMCs expanded on average 2000 fold by a total of 3 weeks. The expanded cell populations were $96-99 \% \mathrm{CD}^{-} \mathrm{CD}^{-} 6^{+}$, as assessed by flow cytometry.

\subsection{Antibodies}

Antibodies (Abs) used for analysis of NK cell receptors and signaling molecules were detailed in Supplementary Table S1. Horseradish peroxidase (HRP)-conjugated anti-mouse and anti-rabbit secondary Abs were from Santa Cruz Biotechnology (Santa Cruz, CA, USA).

\section{4. $R T-P C R$}

To assess the effect of GSK-3 inhibition on ligand expression in KCL-22M cells, total RNA was isolated using the RNeasy kit (QIAGEN, Hilden, Germany) and cDNA was synthesized from $1 \mu \mathrm{g}$ of RNA using the ReverTra Ace qPCR RT kit (Toyobo, Osaka, Japan), according to the manufacturer's instructions. The PCR primers used were detailed in Supplementary Table S2.

\subsection{RNA Interference}

For siRNA-mediated knockdown of GSK-3 $\alpha$ and/or GSK-3 $\beta$, KCL-22 or KCL-22M cells were transfected with 300 pmol of specific siRNA using the Amaxa Nucleofector II system (Lonza, Basel, Switzerland). A total of $1.5 \times 10^{6}$ cells were resuspended in $100 \mu \mathrm{L}$ of Amaxa kit solution $\mathrm{V}$, mixed with siRNA, and transfected using the program T-020. The cells were transfected for $48 \mathrm{~h}$ at $37^{\circ} \mathrm{C}$, washed, and assayed as indicated. The siRNAs 
specific for GSK-3 $\alpha$, GSK-3 $\beta$, and c-Myc were obtained from IDT (Newark, NJ, USA) and had the following sequences: GSK-3 $\alpha, 5^{\prime}$-CAA UAU UGU GAG GCU GAG AUA CUT T-3' (sense) and 5'-AAA GUA UCU CAG CCU CAC AAU AUU GCA-3' (antisense); GSK-3 $\beta$, 5'-AAG AAU CGA GAG CUC CAG AUC AUG A-3' (sense) and 5'-UCA UGA UCU GGA GCU CUC GAU UCU UAA-3' (antisense); and c-Myc, 5'-CUA CAG CGA GUU AGA UAA AGC CCC GAA-3' (sense) and 5'-CGG GGC UUU AUC UAA CUC GCU GUA G-3' (antisense). A second set of siRNAs for c-Myc with the following sequences was used: 5'-CAA UUU GAG GCA GUU UAC AUU AUG GCU-3' (sense) and 5'-CCA UAA UGU AAA CUG CCU CAA AUT G-3' (antisense). Comparable results were obtained with both sets of c-Myc siRNA, and the results shown in the paper were obtained with the first set.

KCL-22M cells with stable knockdown of GSK-3 $\alpha$ (KCL-22M shGSK-3 $\alpha$ ) were generated by transducing KCL-22M cells with the lentiviral GSK-3 $\alpha$ shRNA construct. Lentiviral particles were produced by co-transfection of the 293TN cell line (Systems Biosciences, Palo Alta, CA, USA) with the pLKO.1-puro vector containing a validated shRNA sequence targeting GSK-3 $\alpha$ (MISSION $^{\circledR}$ shRNA TRCN0000038682 or TRCN0000039766; SigmaAldrich) or a non-targeting control shRNA (SHC016; Sigma-Aldrich) and the pPACKH1 packaging plasmid mix (Systems Biosciences) using X-tremeGENE 9 (Roche). The medium was changed after $24 \mathrm{~h}$, and virus-containing supernatant was collected after another $24 \mathrm{~h}$. KCL-22M cells were transduced with lentivirus-containing supernatant in the presence of $10 \mu \mathrm{g} / \mathrm{mL}$ polybrene by spin-infection [34] and then selected with $3 \mu \mathrm{g} / \mathrm{mL}$ puromycin (2 days after transduction). After two rounds of puromycin selection, cells were analyzed for the knockdown of GSK-3 $\alpha$ by immunoblotting and used for further experiments. Comparable results were obtained with both of the GSK-3 $\alpha$ shRNAs, and the results shown in the paper were obtained with TRCN0000039766.

\subsection{NK Cell Degranulation Assay}

The cytotoxic degranulation of NK cells was determined by measuring the cell surface expression of CD107a, as previously described [35]. Briefly, IL-2-stimulated PBMCs or primary expanded NK cells $\left(1 \times 10^{5}\right.$ cells) were mixed with an equal number of KCL-22 M cells in 96-well V-bottom culture plates (Corning Costar, NY, USA) and incubated for $2 \mathrm{~h}$ at $37^{\circ} \mathrm{C}$. For the blockade of NK activating receptors, Fc receptors on IL-2-stimulated PBMCs or primary expanded NK cells were blocked with human Fc Receptor Binding Inhibitor (eBioscience, San Diego, CA, USA) and then incubated with $20 \mu \mathrm{g} / \mathrm{mL}$ control IgG1 or Abs to the indicated NK activating receptors for $30 \mathrm{~min}$ at $4{ }^{\circ} \mathrm{C}$ prior to mixing with target cells. The cell pellets were resuspended in flow cytometry buffer (phosphate-buffered saline [PBS] with 1\% FBS) and stained with anti-human CD3-PerCP, anti-human CD56-PE, and anti-human CD107a-FITC Abs for $35 \mathrm{~min}$ in the dark at $4{ }^{\circ} \mathrm{C}$. Lymphocytes were gated on forward and side scatter characteristics, and the CD107a expression on CD3 ${ }^{-} \mathrm{CD}^{-} 6^{+} \mathrm{NK}$ cells was analyzed by flow cytometry using a FACS Accuri C6 (BD Biosciences, Franklin Lakes, NJ, USA) and FlowJo software (ver.10, Treestar, Ashland, OR, USA).

\subsection{NK Cell Intracellular IFN- $\gamma$ Production Assay}

IL-2-stimulated PBMCs $\left(1 \times 10^{5}\right.$ cells $)$ were stimulated with an equal number of KCL22M cells for $1 \mathrm{~h}$ at $37^{\circ} \mathrm{C}$. Then, brefeldin A (GolgiPlug; BD Biosciences) and monensin (GolgiStop; BD Biosciences) were added, and followed by incubation for an additional $5 \mathrm{~h}$, for a total of $6 \mathrm{~h}$. The cells were first stained with anti-human CD3-PerCP and anti-human CD56-PE antibodies for $30 \mathrm{~min}$ in the dark at $4{ }^{\circ} \mathrm{C}$. Samples were then washed twice with FACS buffer and incubated in BD Cytofix/Cytoperm solution (BD Biosciences) for $20 \mathrm{~min}$ in the dark at $4{ }^{\circ} \mathrm{C}$. The cells were then washed twice with BD Perm/Wash buffer (BD Biosciences), stained with anti-human IFN- $\gamma$-FITC overnight in the dark at $4{ }^{\circ} \mathrm{C}$, washed again, and analyzed by flow cytometry gated on $\mathrm{CD}^{-}{ }^{-} \mathrm{CD} 56^{+} \mathrm{NK}$ cells. 


\subsection{NK Cell Cytotoxicity Assay}

For the europium-based cytotoxicity assay, KCL-22M cells were loaded with $40 \mu \mathrm{M}$ BATDA reagent (Perkin Elmer, Waltham, MA, USA) for $30 \mathrm{~min}$ at $37^{\circ} \mathrm{C}$. Cells were then washed in medium containing $1 \mathrm{mM}$ sulfinpyrazone (Sigma-Aldrich), resuspended at $1 \times 10^{6}$ cells $/ \mathrm{mL}$ in the medium, and incubated with primary expanded NK cells or purified NK cells in the presence of sulfinpyrazone for $2 \mathrm{~h}$ at $37^{\circ} \mathrm{C}$. Plates were mixed briefly and centrifuged at $1400 \mathrm{rpm}$ for $5 \mathrm{~min}$. Supernatant $(20 \mu \mathrm{L})$ was incubated with $200 \mu \mathrm{L}$ of $20 \%$ europium solution (Perkin Elmer) in $0.3 \mathrm{M}$ acetic acid for $5 \mathrm{~min}$, and target cell lysis was detected on a VICTOR X4 multi-label plate reader (Perkin Elmer).

\subsection{Immunoblot Analysis}

KCL-22M cells depleted of GSK-3 were washed with ice-cold PBS and lysed with a lysis buffer [50 mM Tris- $\mathrm{HCl}$ (pH 7.5), $150 \mathrm{mM} \mathrm{NaCl}, 1 \%$ Triton X-100, $5 \mathrm{mM}$ EDTA, $1 \mathrm{mM}$ $\mathrm{NaVO}_{3}, 50 \mathrm{mM} \mathrm{NaF}, 1 \mathrm{mM}$ PMSF, and protease inhibitor cocktail (Thermo Fisher Scientific)] for $30 \mathrm{~min}$ on ice. Cell lysates were then centrifuged to remove cell debris, including the nuclei, and supernatants were harvested. The protein concentration was determined with the Micro BCA protein assay kit (Pierce, Appleton, WI, USA). Lysates were diluted with $4 \times$ NuPAGE LDS sample buffer (Invitrogen) containing $50 \mathrm{mM}$ DTT. Equal amounts of protein from each sample were resolved on $8 \%$ SDS-PAGE gels and transferred onto PVDF membranes (Millipore, Burlington, MA, USA) in transfer buffer [25 mM Tris, $192 \mathrm{mM}$ glycine, $20 \%(v / v)$ methanol]. Membranes were blocked with 5\% skim milk in TBS-T (TBS with $0.1 \%$ Tween 20 ) for $1 \mathrm{~h}$ at room temperature (RT), incubated with primary Abs overnight at $4{ }^{\circ} \mathrm{C}$, and then incubated with HRP-conjugated secondary Abs for $1 \mathrm{~h}$ at RT. Blots were developed with SuperSignal West Pico (Pierce) and signals were detected using an LAS-4000 system (Fujifilm, Midtown West, Tokyo, Japan). All uncropped western blot figures can be found in Supplementary Materials.

\subsection{In Vivo Leukemia Clearance Assay}

To assess whether GSK-3 $\alpha$ inhibition affects cancer surveillance by NK cells in vivo, we used a lymphoma clearance assay [36], modified to compare the killing of different tumors by human NK cells in the same immune-deficient mice. Briefly, 9-10-week-old NOD/ShiLtJ-Rag2 ${ }^{\text {em1AMC } I l 2 r g e m 1 A M C}$ (NRG) mice were purchased from JA BIO (Suwonsi, Gyeonggido, Korea) and injected intraperitoneally (i.p.) with $200 \mathrm{U} / \mathrm{mL}$ rIL-2-activated primary expanded NK cells $\left(1 \times 10^{6}\right.$ cells). KCL-22M shControl cells were labeled with a carboxyfluorescein succinimidyl ester (CFSE) ( $3 \mu \mathrm{M}$; Invitrogen), while KCL-22M shGSK$3 \alpha$ cells were labeled with FarRed $(1 \mu \mathrm{M}$; Invitrogen). The cells were mixed in a 1:1 ratio $\left(1 \times 10^{6}\right.$ cells per each cell type $)$ and injected i.p. into NRG mice. After $4 \mathrm{~h}$, peritoneal cells were collected and analyzed by flow cytometry, and rejection of KCL-22M shGSK-3 $\alpha$ cells relative to KCL-22M shControl cells was calculated as follows: ratio of residual cancer cells $=$ residual KCL-22M shGSK-3 $\alpha$ cells $(\%) /$ residual KCL-22M shControl cells (\%).

\subsection{Statistical Analysis}

Each experiment was performed in duplicate and repeated independently at least three times. Two groups were compared using two-tailed Student's $t$-tests. Differences between multiple groups were analyzed by one-way analysis of variance (ANOVA). All data were analyzed using GraphPad Prism software (ver.5.00, GraphPad Software, Inc., San Diego, CA, USA). Statistical significance was defined as $p<0.05$, and the degree of significance is indicated as follows: ${ }^{*} p<0.05,{ }^{* *} p<0.01$, and ${ }^{* * *} p<0.001$.

\section{Results}

3.1. Pharmacologic Inhibition of GSK-3 in TKI-Resistant CML Cells Enhances Their Expression of NKG2D Ligands and Susceptibility to NK Cells

Previously, we showed that GSK-3 $\beta$ acts as a negative regulator of multiple NK activation signals, mainly NKG2D [26]. Moreover, we provided evidence that NK cells could 
efficiently kill CML cells harboring a point mutation (T315I) that renders them resistant to all approved BCR-ABL1 TKIs, which remain a major clinical challenge [37]. We hypothesized that GSK-3 inhibitors might hold promise in the treatment of leukemia, including those with multi-TKI resistance, by promoting cancer immunosurveillance in addition to their direct anticancer activity. To address this possibility further, we investigated the effect of GSK-3 inhibition in TKI-resistant CML cells on the expression of ligands for NK cell activating receptors, with a focus on ligands for NKG2D. To this end, KCL-22M cells, a human CML-blast crisis cell line harboring the T315I mutation in the BCR-ABL1 kinase domain [33], was used. This cell line triggered NK cell cytotoxic degranulation in an NKG2D-dependent manner, as revealed by blockade of NKG2D with a specific $\mathrm{Ab}$ (Figure 1A).

A
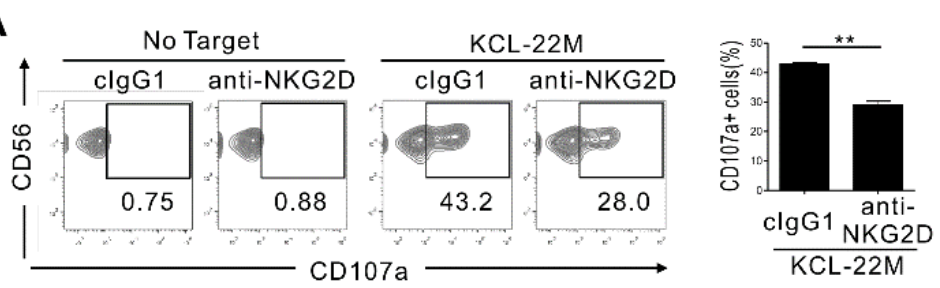

B
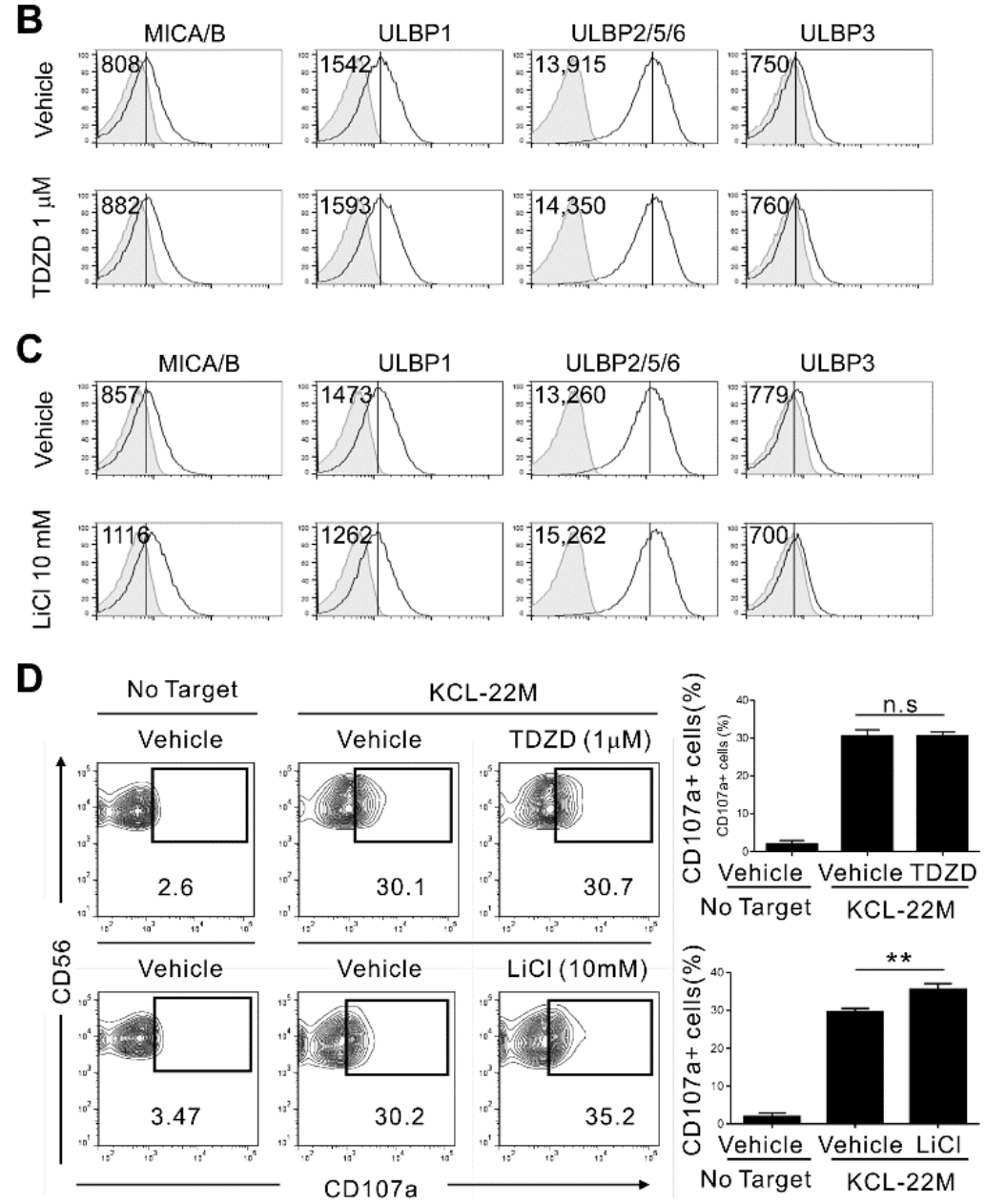

Figure 1. Inhibition of GSK-3 enhances NKG2DL expression and NK cell-mediated cytotoxicity against KCL-22M cells. (A) KCL-22M cells were pretreated with IM (5 $\mu \mathrm{M})$ for $48 \mathrm{~h}$, washed, and then mixed with expanded primary NK cells preincubated with a monoclonal Ab to the NKG2D receptor 
$(20 \mu \mathrm{g} / \mathrm{mL})$ for $2 \mathrm{~h}$. Degranulation of NK cells was measured by the surface expression of CD107a on $\mathrm{CD}^{-}{ }^{-} \mathrm{CD} 56^{+} \mathrm{NK}$ cells. Representative flow cytometry profile (left) and summary graph (right) demonstrating the percentage of $\mathrm{CD}_{107 \mathrm{a}^{+}}$NK cells. $(\mathbf{B}, \mathbf{C})$ The surface expression of NKG2DL (MICA/B, ULBP1, ULBP2/5/6, and ULBP3) was analyzed by flow cytometry on KCL-22M cells treated with the GSK-3 inhibitor TDZD-8 (1 $\mu \mathrm{M}$; GSK-3 $\beta$-selective) (B) or LiCl (10 mM; pan-GSK-3) (C) for $48 \mathrm{~h}$. (D) KCL-22M cells were pretreated with GSK-3 inhibitors as in (B,C) for $48 \mathrm{~h}$, and then mixed with IL-2-stimulated PBMCs for measurement of degranulation. Representative flow cytometry profile (left) and summary graph (right) demonstrating the percentage of $\mathrm{CD} 107 \mathrm{a}^{+}$on $\mathrm{CD}^{-} \mathrm{CD}^{-} 6^{+} \mathrm{NK}$ cells. Values represent the means \pm s.d. Data are representative of at least three independent experiments. ${ }^{* *} p<0.01$.

GSK-3 was blocked with two different GSK-3 inhibitors, TDZD-8 (a GSK-3 $\beta$-specific inhibitor) and $\mathrm{LiCl}$ (a pan-GSK-3 inhibitor). Thereafter, the surface expression of NKG2D ligands (NKG2DL), including MICA/B, ULBP1, ULBP2/5/6, and ULBP3, was assessed by flow cytometry. $\mathrm{LiCl}$ induced a clear upregulation of ULBP2/5/6, and, to a marginal extent, MICA/B on KCL-22M cells after $48 \mathrm{~h}$ of treatment, whereas TDZD-8 failed to upregulate ULBP2/5/6 (Figure 1B,C). Accordingly, LiCl but not TDZD-8 significantly increased the susceptibility of KCL-22M cells to NK cell cytotoxicity, as assessed by NK cell degranulation in IL-2-stimulated PBMCs (Figure 1D) and NK cell cytotoxicity in IL-2-stimulated purified NK cells (Supplementary Figure S1). The upregulation of NKG2DL following $\mathrm{LiCl}$ treatment was confirmed at the level of gene expression with a moderate increase in MICA mRNA, corroborating the previous study [28], and a strong increase in ULBP2 mRNA (Supplementary Figure S2). Collectively, although not striking, GSK-3 inhibition led to the moderate upregulation of NKG2DL, particularly ULBP2, and enhanced the susceptibility of TKI-resistant KCL-22M cells to NK cell cytotoxicity. Moreover, the selective effect of $\mathrm{LiCl}$ but not TDZD-8 in such a context raised the possibility of an isoform-specific role of GSK-3 in NKG2DL regulation.

\subsection{GSK-3 $\alpha$ Selectively Regulates NKG2DL Expression and Cytolysis by NK Cells}

Next, the individual contributions of GSK-3 isoforms to the regulation of NKG2DL in TKI-resistant CML cells was investigated using siRNAs specific for GSK-3 $\alpha$ or GSK-3 $\beta$ to rule out potential off-target effect of GSK-3 inhibitor and probe the specific role of GSK-3. A selective and significant knockdown of GSK-3 $\alpha$ and/or GSK-3 $\beta$ was detected in the KCL-22M cells after transfection with the corresponding siRNAs (Figure 2A).

Knockdown of GSK-3 $\alpha$ but not GSK-3 $\beta$ caused a notable upregulation in the levels of ULBP2/5/ 6 but no other ULBPs in KCL-22M cells (Figure 2B). In addition, the effect of GSK-3 $\alpha$ knockdown on ULBP2/5/6 upregulation was nullified by combined knockdown of GSK-3 $\beta$, suggesting a reciprocal effect of GSK-3 isoforms on the regulation of ULBP2/5/6. In comparison, the levels of MICA/B were moderately increased by individual knockdown of GSK-3 $\alpha$ or GSK-3 $\beta$, and further upregulated by their combined knockdown. As expected, quantitative real-time PCR confirmed the enhanced expression of ULBP2, and, to a lesser extent, ULBP1 and MICA by GSK-3 $\alpha$ knockdown and upregulation of MICA by GSK-3 $\beta$ knockdown (Supplementary Figure S3). Thus, these results suggest non-redundant roles for GSK-3 $\alpha$ and GSK-3 $\beta$ in the regulation of NKG2DL, particularly ULBP2 $/ 5 / 6$. Of interest, knockdown of GSK-3 $\alpha$ had similar effects on the regulation of ULBP2/5/6 and MICA/B in KCL-22 cells harboring wild-type BCR-ABL1 (Supplementary Figure S4), suggesting that GSK-3 regulates NKG2DL expression independently of oncogenic BCR-ABL1 mutations conferring TKI resistance.

We next assessed whether such a differential regulation of NKG2DL by GSK-3 isoforms on KCL-22M cells affects their susceptibility to NK cell-mediated lysis. To this end, primary NK cells from healthy donors were prepared using cytokines and a feeder-based expansion protocol adopted for use in clinical trials, and then used as effector cells. Knockdown of GSK-3 $\alpha$ but not GSK-3 $\beta$ rendered KCL-22M cells more susceptible to NK cell-mediated lysis (Figure 2C), correlating with the increased levels of NKG2DL, particularly ULBP2/5/6. Consistently, NK cell degranulation against KCL-22M cells was increased more significantly 
by knockdown of GSK-3 $\alpha$ than GSK-3 $\beta$ (Figure 2D). This increased degranulation was largely dependent on the NKG2D pathway, as determined by Ab-mediated blockade of NKG2D. Likewise but to a lesser extent, NK cell IFN- $\gamma$ expression was significantly upregulated after depletion of GSK-3 $\alpha$ but not GSK-3 $\beta$ in KCL-22M cells (Supplementary Figure S5). These results suggest that expression of NKG2DL, especially ULBP2/5/6, is regulated by the GSK- $3 \alpha$ isoform and preferentially controls the susceptibility of KCL$22 \mathrm{M}$ cells to NK cell-mediated cytotoxicity.
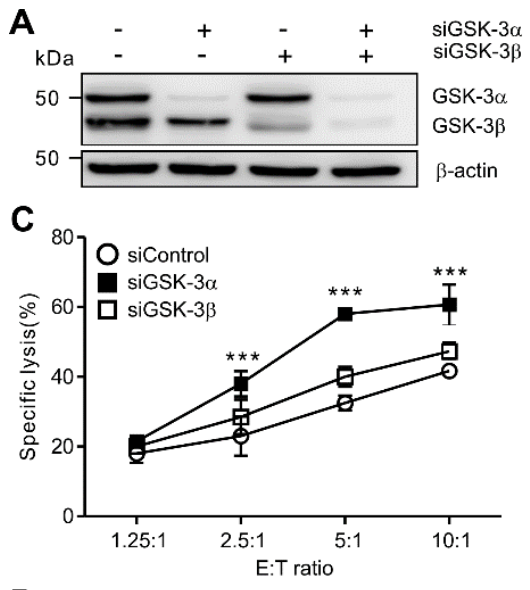

D
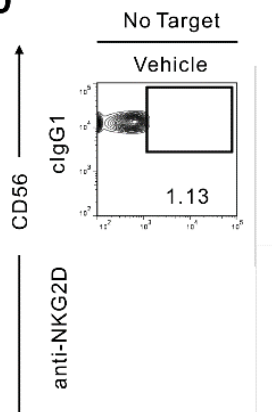

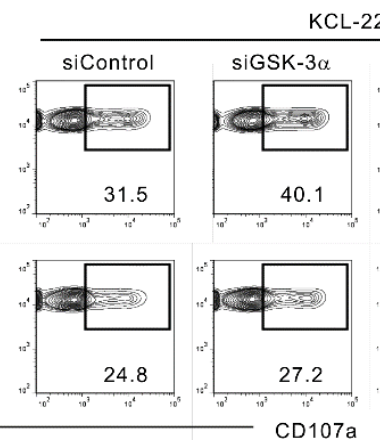

B
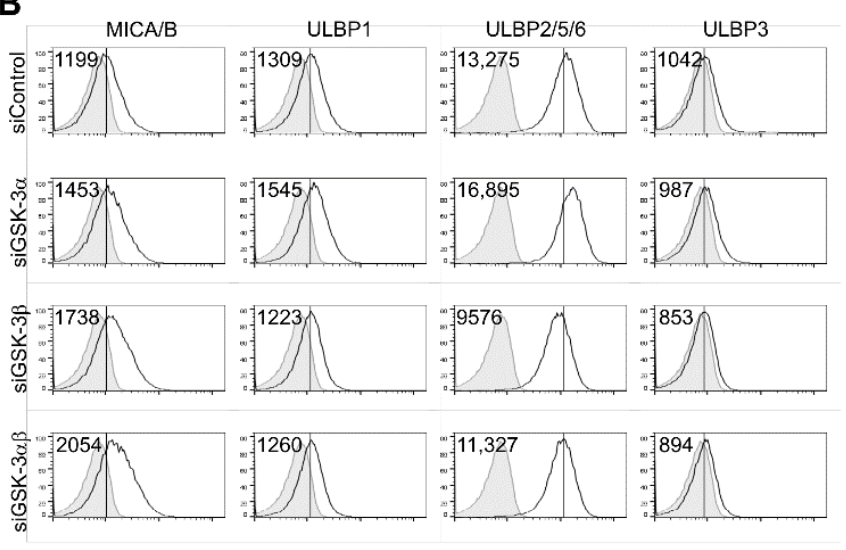

KCL-22M
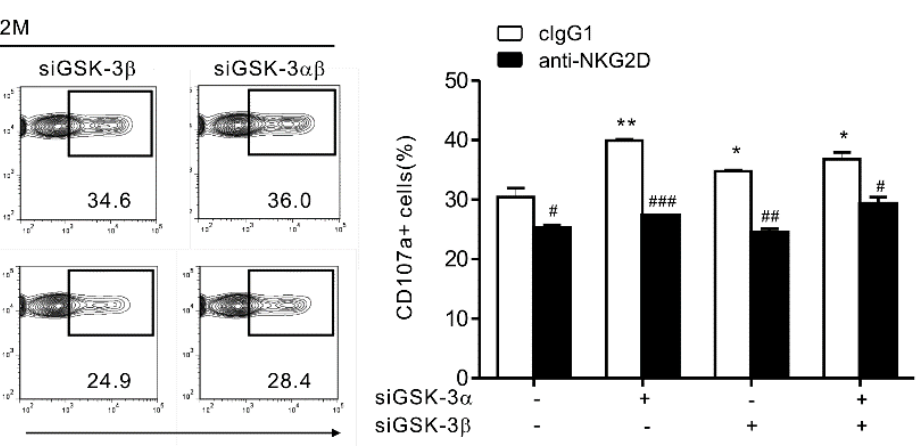

Figure 2. GSK-3 $\alpha$ selectively regulates NKG2DL expression on TKI-resistant KCL-22M cells and their cytolysis by NK cells. (A) Total cell lysates of KCL-22M cells transfected with control siRNA or siRNAs specific for GSK-3 $\alpha$ and/or GSK-3 $\beta$ for $48 \mathrm{~h}$ were immunoblotted for GSK-3 $\alpha / \beta$ and actin. (B) After siRNA-mediated knockdown, KCL-22M cells were analyzed for the surface expression of NKG2DL (MICA/B, ULBP1, ULBP2/5/6, and ULBP3) by flow cytometry. (C) NK cell cytotoxicity against KCL-22M cells depleted of GSK-3 $\alpha$ and/or GSK-3 $\beta$ was assessed using a europium-based cytotoxicity assay with expanded primary NK cells at the indicated effector to target (E:T) cell ratios. (D) Degranulation of NK cells against KCL-22M cells depleted of GSK-3 $\alpha$ and/or GSK-3 $\beta$ was measured using expanded primary NK cells in the absence or presence of NKG2D blockade. Representative flow cytometry profile (left) and summary graph (right) demonstrating the percentage of $\mathrm{CD} 107 \mathrm{a}^{+}$on $\mathrm{CD} 3{ }^{-} \mathrm{CD} 56^{+} \mathrm{NK}$ cells. Values represent the means $\pm \mathrm{s}$.d. Data are representative of at least three independent experiments. ${ }^{*}, \#<0.05 ;{ }^{* *}, \# \# p<0.01$; ${ }^{* * *}, \# \#+0.001$.

\subsection{GSK-3 $\alpha$ Regulates ULBP2/5/6 by PI3K/Akt- and c-Myc-Dependent Pathways}

We next studied the mechanisms underlying the regulation of NKG2DL by GSK-3 $\alpha$, with a focus on ULBP2/5/6. PI3K and the mitogen-activated protein kinase (MAPK) ERK are among the signaling molecules regulated by GSK-3 [26,38,39] and are also important for NKG2DL upregulation [40-42]. Their role in the regulation of NKG2DL and consequent triggering of NK cell cytotoxicity was therefore investigated. GSK-3 $\alpha$ knockdown enhanced the phosphorylation of Akt, which is downstream of PI3K activation, but did not affect the phosphorylation of ERK (Figure 3A). 
A

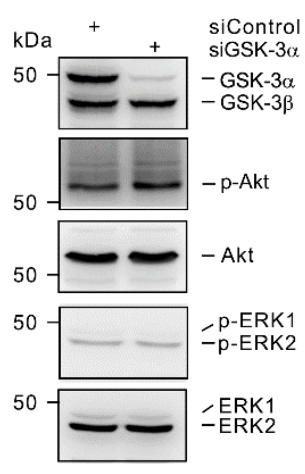

B

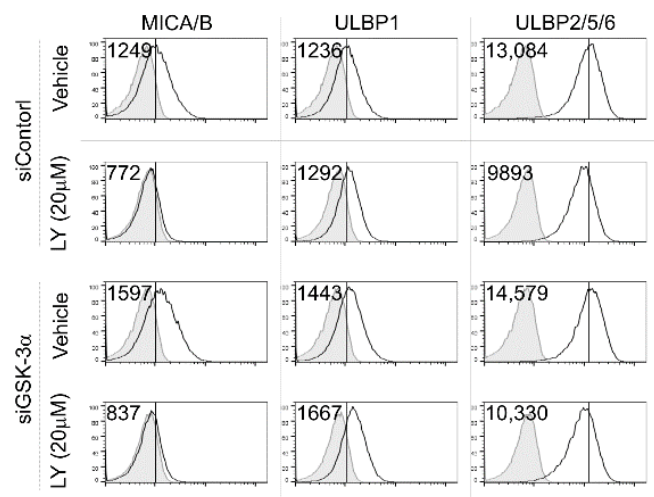

C
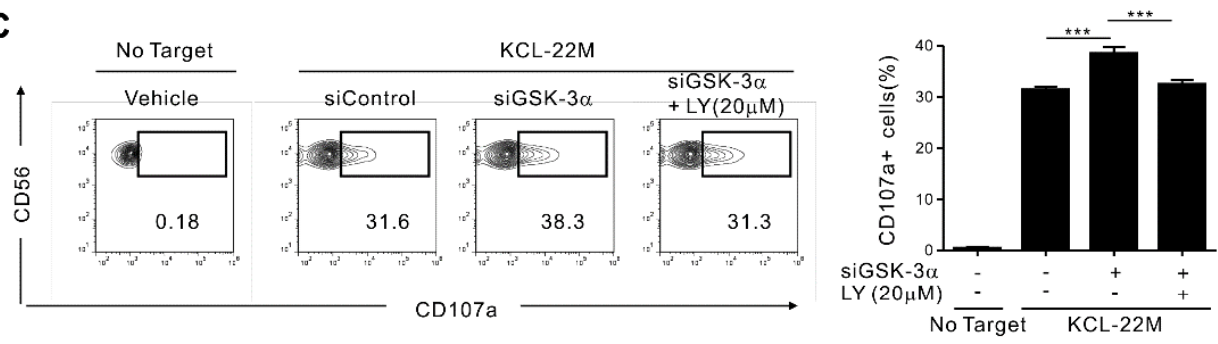

D

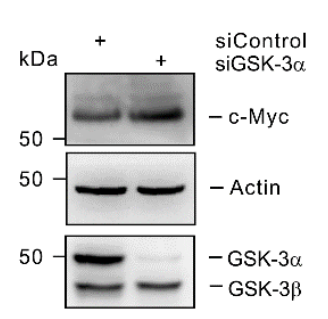

E

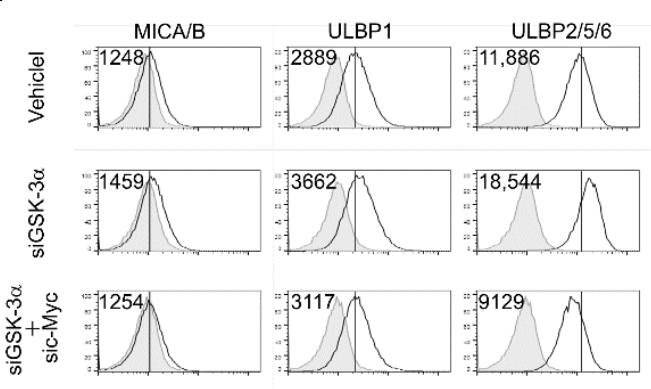

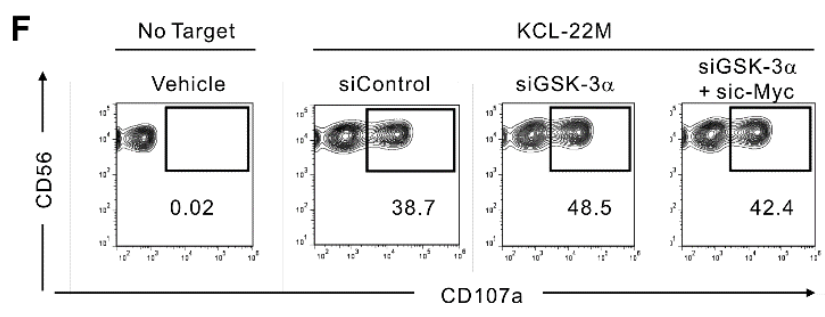

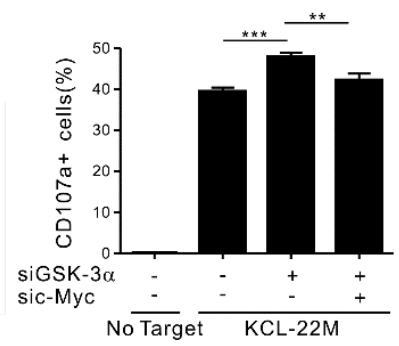

Figure 3. GSK-3 $\alpha$ knockdown enhances NKG2DL expression via Akt signaling and c-Myc activity. (A) Total cell lysates from KCL-22M cells transfected with control siRNA or GSK-3 $\alpha$-specific siRNAs for 48 h were immunoblotted for GSK-3 $\alpha / \beta$, p-Akt, Akt, p-ERK1/2, and ERK1/2. (B) Analysis of NKG2DL surface expression on KCL-22M cells after siRNA-mediated knockdown of GSK-3 $\alpha$ in the absence or presence of the PI3K inhibitor LY (20 $\mu \mathrm{M})$ for $48 \mathrm{~h}$. (C) Degranulation of NK cells in PBMCs against KCL-22M cells after siRNA-mediated knockdown of GSK-3 $\alpha$ in the absence or presence of the PI3K inhibitor LY $(20 \mu \mathrm{M})$ for $48 \mathrm{~h}$. Representative flow cytometry profile (left) and summary graph (right) demonstrating the percentage of $\mathrm{CD} 107 \mathrm{a}^{+}$on $\mathrm{CD}^{-} \mathrm{CD}^{-} 6^{+} \mathrm{NK}$ cells. (D) Total lysates of KCL-22M cells transfected with control siRNA or a GSK-3 $\alpha$-specific siRNA for $48 \mathrm{~h}$ were immunoblotted for c-Myc, $\beta$-actin, and GSK- $3 \alpha / \beta$. (E) Analysis of NKG2DL surface expression on KCL-22M cells after siRNA-mediated knockdown of GSK-3 $\alpha$ or GSK-3 $\alpha$ and c-Myc. (F) Degranulation of NK cells in PBMCs against KCL-22M cells depleted of GSK-3 $\alpha$ or GSK-3 $\alpha$ and c-Myc. Representative flow cytometry profile (left) and summary graph (right) demonstrating the percentage of $\mathrm{CD} 107 \mathrm{a}^{+}$on $\mathrm{CD}^{-} \mathrm{CD}^{-} 6^{+} \mathrm{NK}$ cells. Values represent the means \pm s.d. Data are representative of at least three independent experiments. ${ }^{* *} p<0.01 ;{ }^{* * *} p<0.001$. 
Accordingly, the upregulation of ULBP2/5/6 and MICA/B following GSK-3 $\alpha$ knockdown was nullified by treatment with LY294002 (LY), a pan-PI3K inhibitor (Figure 3B). Moreover, the same treatment reduced the baseline levels of ULBP2/5/6 and MICA/B on control KCL-22M cells, suggesting a broad impact of the PI3K pathway in NKG2DL regulation. Similar to the results with NKG2DL, we found a significant decrease in NK cell degranulation against GSK-3 $\alpha$-depleted KCL-22M cells upon LY treatment (Figure 3C).

We further investigated the involvement of c-Myc in NKG2DL regulation, given the close association of c-Myc with the PI3K/Akt pathway in Ras or oncogenic BCR-ABL1 signaling $[43,44]$ and with the expression of ULBP1/2/3 in AML [45]. c-Myc is also a known substrate for GSK- $3 \alpha$, which phosphorylates c-Myc at a regulatory threonine residue and promotes its degradation via the ubiquitin/proteasome pathway [46,47]. As expected, GSK-3 $\alpha$ knockdown led to the accumulation of c-Myc in KCL-22M cells (Figure 3D). The observed upregulation of NKG2DL after GSK-3 $\alpha$ knockdown was markedly diminished by additional knockdown of c-Myc (Figure 3E), correlating with decreased NK cell degranulation against KCL-22M cells (Figure 3F). Similar results on NKG2DL regulation were obtained by treatment with a pharmacological inhibitor of c-Myc, 10058-F4 (F4) (Supplementary Figure S6). These data collectively suggest that GSK-3 $\alpha$ regulates NKG2DL expression in a manner dependent on PI3K/Akt and c-Myc activity.

\subsection{GSK-3 $\alpha$ Knockdown Enhances the Susceptibility of KCL-22M Cells to NK Cells In Vivo}

We next addressed whether GSK-3 $\alpha$ modulation also enhances the susceptibility of KCL-22M cells to NK cell-mediated killing in vivo. To this end, we first established KCL$22 \mathrm{M}$ cells with stable knockdown of GSK-3 $\alpha$ after transduction with a lentiviral vector containing shRNA sequences targeting GSK-3 $\alpha$ and antibiotic selection. The selected cells were referred to as KCL-22M-shGSK-3 $\alpha$ or KCL-22M-shControl cells, respectively (Figure 4A).

Similar to the results with siRNA-mediated knockdown, KCL-22M-shGSK-3 $\alpha$ cells exhibited enhanced upregulation of ULBP2/5/6 (Figure 4B) and increased susceptibility to NK cell cytolysis (Figure 4C), and triggered increased degranulation of NK cells (Figure 4D). For the in vivo study, we used a lymphoma clearance assay [36] modified to compare the clearance of different tumors by human NK cells in the same mice. Specifically, equal numbers of KCL-22M-shGSK-3 $\alpha$ and KCL-22M-shControl cells were co-injected i.p. into immune-deficient NRG mice lacking NK cells after an injection of human primary NK cells (Figure 4E). To facilitate their identification, KCL-22M-shGSK-3 $\alpha$ and KCL-22MshControl cells were labeled with CellTrace FarRed and CFSE, respectively, in addition to forward scatter (FSC) vs. side scatter (SSC) gating (Supplementary Figure S7). Analysis of the peritoneal fluid by flow cytometry revealed a significant increase in the clearance of KCL-22M-shGSK-3 $\alpha$ cells over KCL-22M-shControl cells at $4 \mathrm{~h}$ post-injection (Figure 4F). The preferential clearance of KCL-22M-shGSK-3 $\alpha$ cells was mediated by NK cells, as there was comparable recovery of the two cell populations in the absence of human primary NK cells. Although it requires further assessment of dead tumor cells among the peritoneal cells, these results suggest that GSK-3 $\alpha$ inhibition in TKI-resistant KCL-22M cells enhances NK cell-mediated surveillance in vivo. 
A
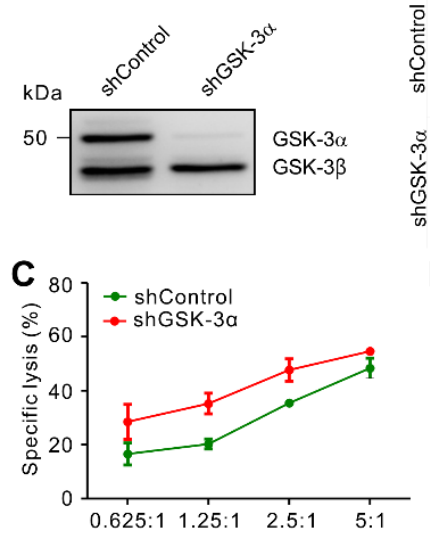

E

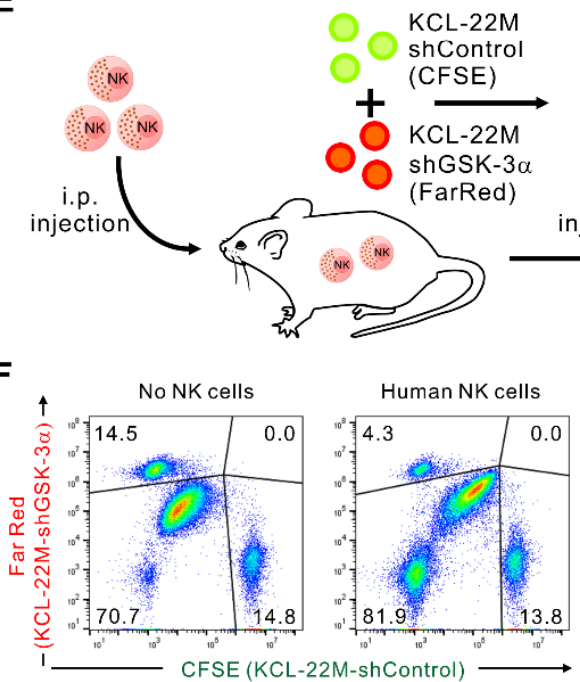

B
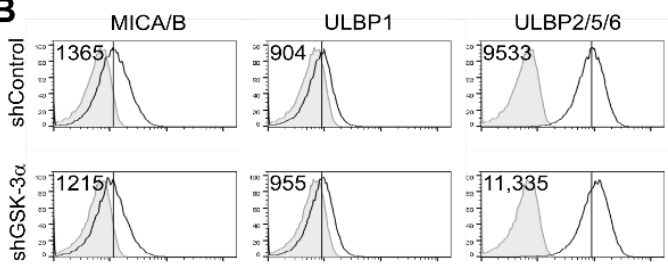

D
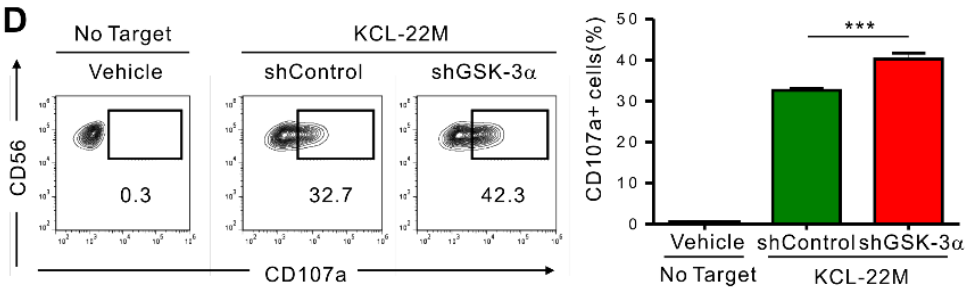
1L (CD155/PVR and CD112/Nectin-2) on KCL-22M-shGSK-3 $\alpha$ cells were comparable to those on KCL-22M-shControl cells (Figure 5A), suggesting little or no effect of GSK-3 $\alpha$ on DNAM-1L regulation. These results are consistent with a previous study showing no effect of GSK-3 inhibitors on CD155/PVR levels [28]. By contrast, we found a noticeable upregulation of NKp30L (B7-H6) on KCL-22M-shGSK-3 $\alpha$ cells compared with KCL-22MshControl cells, indicating an unexpected involvement of GSK-3 $\alpha$ in the regulation of NKp30L. This notion was supported by the significant contribution of NKp30 to NK cell degranulation against KCL-22M-shGSK-3 $\alpha$ cells upon receptor blockade (Figure 5B), in contrast to the marginal contribution of NKp30 to NK cell lysis of KCL-22M-shControl cells in the absence of GSK-3 $\alpha$ inhibition (Supplementary Figure S8) [37].

A
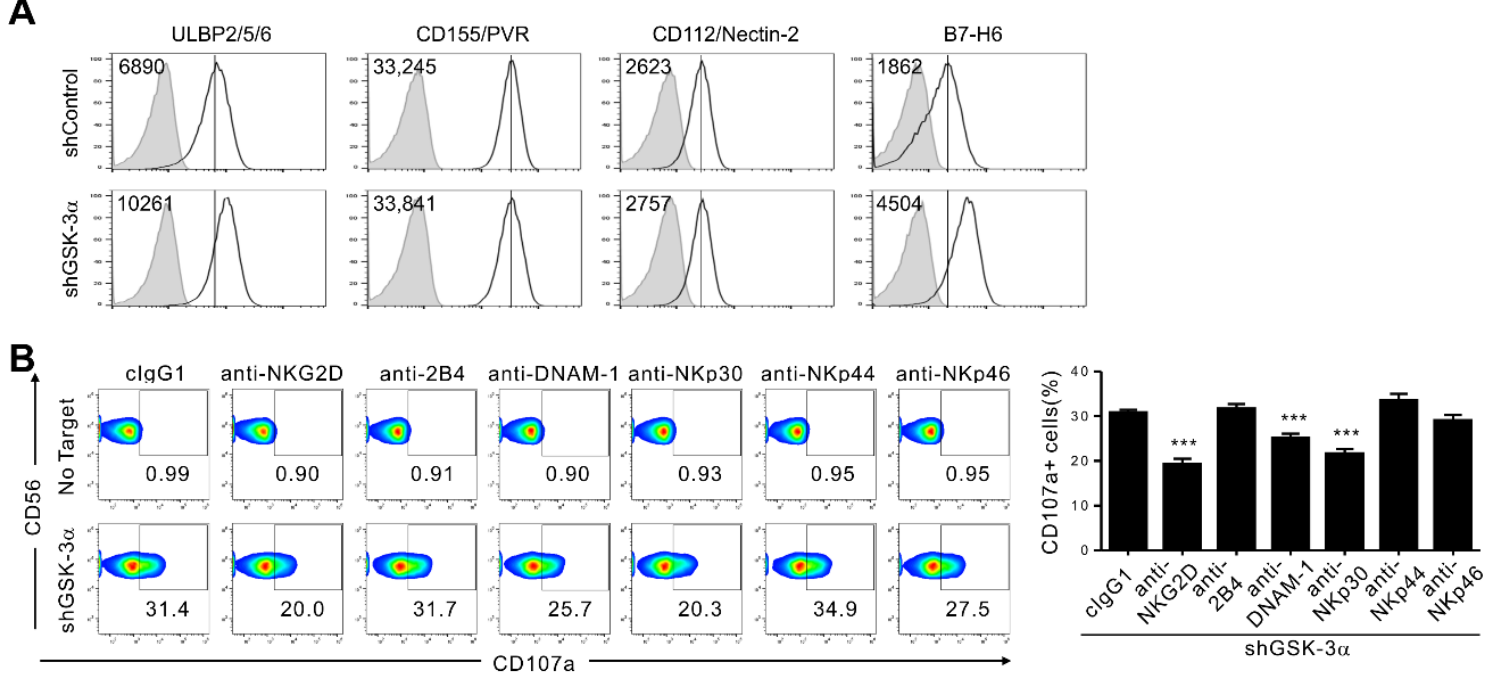

Figure 5. GSK-3 $\alpha$ knockdown induces the upregulation of NKp30L (B7-H6) but not DNAM-1L (CD155 and CD112). (A) Analysis of ULBP2/5/6, ligands of the NKG2D receptor; CD155/PVR and CD112/nectin-2, ligands of the DNAM-1 receptor; and B7-H6, the ligand of the NKp30 receptor, on KCL-22M cells transduced with control shRNA (shControl) or with stable knockdown of GSK-3 $\alpha$ (shGSK-3 $\alpha$ ). (B) KCL-22M cells transduced with lentivirus expressing an shRNA specific for GSK-3 $\alpha$ were mixed with expanded primary NK cells preincubated with blocking Abs to the indicated receptors $(20 \mu \mathrm{g} / \mathrm{mL})$ for $2 \mathrm{~h}$. Degranulation was measured by the expression of CD107a on CD3 ${ }^{-} \mathrm{CD}^{+} 6^{+} \mathrm{NK}$ cells. Representative flow cytometry profile (left) and summary graph (right) demonstrating the percentage of CD107a ${ }^{+} \mathrm{NK}$ cells. Values represent the means \pm s.d. Data are representative of at least three independent experiments. ${ }^{* * *} p<0.001$.

\section{Discussion}

Herein, we provide evidence that GSK-3, specifically GSK-3 $\alpha$, is a pivotal regulator of the expression of ligands for activating receptors, including NKG2D and NKp30, but not DNAM-1. Using a cell line model of TKI-resistant CML, we found that this regulation of NK cell activating ligands by GSK-3 $\alpha$ was independent of an oncogenic BCR-ABL1 mutation conferring TKI resistance and occurred at the level of gene transcription as well as cell surface protein expression. Moreover, the finding that PI3K/Akt signaling and c-Myc activity were involved in this response provides new insights into the molecular mechanisms underlying the regulation of NK cell activating ligands and consequent target susceptibility by GSK-3 $\alpha$. Importantly, the therapeutic relevance of this finding was supported by our identification of preferential clearance of TKI-resistant KCL-22M cells depleted of GSK- $3 \alpha$ by NK cells in vivo. Thus, our results suggest that GSK-3 $\alpha$ is likely the primary GSK-3 isoform restraining the expression of NKG2DL, particularly ULBP2/5/6, and NKp30L by TKI-resistant KCL-22M cells and demonstrate that GSK-3 $\alpha$ inhibition appears a relevant strategy to enhance target cell susceptibility to NK cell-mediated lysis. In support, similar regulation by GSK- $3 \alpha$ but not GSK-3 3 of the expression of ULBP2/5/6 among other NKG2DL and NKp30L (B7-H6) and target susceptibility to NK cells was 
observed with K562 cells, a human CML cell line despite the difference in the pattern of ligand expression (Supplementary Figure S9).

GSK- 3 includes two isoforms, GSK-3 $\alpha$ and GSK-3 $\beta$, which control diverse cellular functions in both redundant and isoform-specific manners, depending on the context $[7,48,49]$. Previously, we demonstrated that GSK-3 $\beta$ but not GSK- $3 \alpha$ negatively regulates the functions of human NK cells triggered by multiple activating receptors, including NKG2D, 2B4, and NKp30, and against K562 CML cells [26]. Thus, the dominant regulation of the activating ligands by GSK- $3 \alpha$, as shown here, highlights the differential roles of GSK- $3 \alpha$ and GSK-3 $\beta$ in cancer surveillance by NK cells, further supporting the notion of isoformspecific functions of GSK-3. Inhibition of GSK-3 $\alpha$ upregulated the expression of NKG2DL, particularly ULBP2/5/6 and to a lesser extent MICA/B and ULBP1, and NKp30L (B7-H6), but not DNAM-1L (CD155/PVR and CD112/Nectin-2) on TKI-resistant KCL-22M cells, leading to enhanced susceptibility to NK cell-mediated lysis. GSK- $3 \beta$ knockdown also induced a moderate upregulation of MICA/B but downregulated the levels of ULBP2/5/6, suggesting distinct regulation of activating ligands by different GSK-3 isoforms. Evaluation of MICA/B and ULBP2/5/6 at the level of gene expression revealed a selective regulation of ULBP2 by GSK-3 $\alpha$ but a common involvement of both isoforms in the regulation of MICA but not MICB. This observation is consistent with a previous study showing upregulation of MICA but not MICB on multiple myeloma by pharmacological inhibitors of GSK-3 targeting GSK-3 $\beta$ or both isoforms [28].

A mechanistic study indicated that NKG2DL upregulation by GSK-3 $\alpha$ inhibition could be attributed to an increase in PI3K/Akt signaling and c-Myc activity. Consistent with this, knockdown of GSK-3 $\alpha$ increased the levels of Akt phosphorylation and c-Myc, both of which were required for the upregulation of activating ligands. PI3K/Akt is considered a key signaling pathway in the regulation of NKG2DL such as ULBP1/2/3 and MICA/B $[40,41]$. Recent studies also support this notion by showing the upregulation of MICA/B on multiple tumor cell types via the PI3K/Akt pathway [50,51]. Intriguingly, PI3K/Akt signaling has been implicated in phosphorylation of GSK-3 $\alpha$ and GSK-3 $\beta$ at regulatory serine residues, resulting in GSK-3 inhibition [20,52]. Given our result that GSK$3 \alpha$ inhibition increased Akt phosphorylation, we speculate that there is a feedback loop between the PI3K/Akt pathway and GSK-3 $\alpha$ for the regulation of NK activating ligands on leukemia cells. We also reported that knockdown of GSK-3 $\beta$ in NK cells resulted in increased phosphorylation of Akt, potentiating NK cell functions [26]. Thus, such a crossregulation between PI3K/Akt and GSK-3 isoforms appears to be a common mechanism underlying the regulation of NK cell reactivity against leukemia cells according to the context (i.e., activating ligand expression vs. NK cell function). Moreover, c-Myc is often dysregulated and overexpressed in many different tumor types, including leukemia [53,54], and it drives the expression of NKG2DL in a mouse leukemia model [55] and the expression of ULBP1/2/3 in human AML [45]. GSK-3 $\alpha$ is known to phosphorylate c-Myc at threonine 58 , promoting its degradation via the ubiquitin/proteasome pathway $[46,47]$. This regulation is consistent with our data showing increased levels of c-Myc upon GSK-3 $\alpha$ depletion in KCL-22M cells and a previous study showing c-Myc accumulation by pharmacological blockade of pan-GSK-3 in KRAS mutant tumors [56]. However, the involvement of other regulatory mechanism(s) cannot be excluded and merits further investigation, given that GSK-3 is a central hub of many signaling pathways.

Importantly, NKG2DL were not the only ligands regulated by GSK- $3 \alpha$. We found that the NKp30L B7-H6 is also upregulated by GSK-3 $\alpha$ depletion, contributing to the enhanced sensitivity of KCL-22M cells to NK cells. B7-H6 is frequently expressed on the surface of different tumor cells and has recently been shown to be regulated by a mechanism involving c-Myc induction [57]. Given the increased levels of c-Myc upon GSK-3 $\alpha$ knockdown, we speculate that c-Myc is potentially linked to B7-H6 regulation by GSK-3 $\alpha$, which merits further investigation. Moreover, as NKG2DL are frequently downregulated or absent on leukemia blasts and leukemic stem cells $[3,58,59]$, the upregulation of B7-H6 by GSK- $3 \alpha$ inhibition could provide an additional therapeutic target to enhance NK cell reactivity 
against leukemia cells. Moreover, the involvement of other ligands regulated by GSK-3 $\alpha$ cannot be excluded, which warrants further study.

An array of GSK-3 inhibitors with different isoform specificities are available and have been shown to induce apoptosis or growth arrest of various leukemia cell lines and primary leukemia cells [60-63]. A primary concern in the potential clinical application of GSK-3 inhibitors, particularly pan-GSK-3 inhibitors, is their possible stabilization and activation of $\beta$-catenin, which can promote oncogenic transformation $[12,21,63,64]$. This safety concern has encouraged continued interest in developing a strategy to target GSK-3 in an isoform-specific manner. This notion is supported by recent studies showing a potential clinical benefit of selective genetic targeting of GSK-3 $\alpha$ over GSK-3 $\beta$, which inhibited AML progression [60] and myeloid transformation [64] without affecting $\beta$-catenin. In support of this, BRD0705, a GSK-3 $\alpha$-selective inhibitor, induced myeloid differentiation and impaired colony formation in AML cells without affecting normal hematopoietic cells and $\beta$-catenin stability [63]. In this regard, targeted modulation of GSK-3 $\alpha$ may hold promise as a viable strategy to improve NK cell reactivity against leukemia cells in addition to its direct anti-leukemic effects, given the upregulation of NKG2DL and NKp30L in leukemia cells upon GSK-3 $\alpha$ inhibition. Moreover, an increase in activating ligands also occurred in TKI-resistant CML cells carrying the T315I mutation of BCR-ABL1, one of the major cause of mortality in CML patients $[65,66]$. Thus, targeted inhibition of GSK- $3 \alpha$ may provide an alternative therapeutic strategy against refractory/relapsed CML cells with TKI-resistance and possibly other leukemia cells in the context of NK cell-based therapy.

\section{Conclusions}

Altogether, we found that GSK-3 $\alpha$ appears the primary isoform restraining the expression of a subset of ligands for activating receptors such as NKG2D, NKp30 but not DNAM-1, thereby regulating the susceptibility of TKI-resistant CML cells to NK cells in vitro and in vivo. Moreover, the finding of PI3K/Akt signaling and c-Myc in such a context provides an insight into the molecular mechanism of the ligand upregulation by GSK-3 $\alpha$ inhibition. Although further validation is required using different cell types and primary leukemic blasts, the present study may suggest the distinct role of GSK-3 isoforms in the regulation of ligands for NK activating receptors and GSK-3 $\alpha$ modulation as a potential strategy for enhancing anti-tumor reactivity of NK cells.

Supplementary Materials: The following are available online at https:/ / www.mdpi.com/article/ 10.3390/cancers13081802/s1. Figure S1: Inhibition of GSK-3 by LiCl enhances NK cell-mediated cytotoxicity, Figure S2: Inhibition of GSK-3 by LiCl enhances the gene transcription of MICA and ULBP2, Figure S3: GSK-3 $\alpha$ knockdown enhances the gene transcription of NKG2DLs, Figure S4: GSK-3 regulation of NKG2DL expression is independent of BCR-ABL mutation, Figure S5: GSK$3 \alpha$ isoform selectively regulates IFN- $\gamma$ production of NK cells against KCL-22M cells, Figure S6: Inhibition of c-Myc diminishes NKG2DL upregulation by siRNA-mediated knockdown of GSK-3 $\alpha$, Figure S7: FACS gating strategy, Figure S8: NKG2D and DNAM-1 contribute to the degranulation of NK cells against KCL-22M-shControl cells, Figure S9: GSK-3 $\alpha$ knockdown enhances NKG2DL and NKp30L expression on K562 cells and their cytolysis by NK cells, Table S1: List of antibodies used for analysis of NK cells and signaling molecules, Table S2: List of primers used for real-time PCR analyses of the indicated genes.

Author Contributions: N.K., M.Y.K., W.S.C., E.Y., and H.J.L. were involved in data acquisition. N.K., W.S.C., and H.S.K. were involved in data analysis and interpretation. M.Y.K. helped design studies with in vivo lymphoma clearance assay. N.K. and H.S.K. contributed to the conceptual design of the study and writing of the manuscript with an input from all co-authors. All authors have read and agreed to the published version of the manuscript.

Funding: This work was supported by grants from the National Research Foundation funded by the Ministry of Science and ICT (MSIT) of the government of Korea (2019R1A2C2006475), MRC grant (2018R1A5A2020732) funded by the Korean government (MSIT), and partly by a grant (2021IP0003) from the Asan Institute for Life Sciences, Asan Medical Center, Seoul, Korea. 
Institutional Review Board Statement: The study was conducted according to the guidelines of the Declaration of Helsinki, and approved by the Institutional Review Board of Asan Medical Center (2013-0850 and 16 September 2013).

Informed Consent Statement: Informed consent was obtained from all subjects involved in the study.

Data Availability Statement: The data presented in this study are available on reasonable request from the corresponding author.

Conflicts of Interest: The authors declare no conflict of interest.

\section{References}

1. Long, E.O.; Sik Kim, H.; Liu, D.; Peterson, M.E.; Rajagopalan, S. Controlling natural killer cell responses: Integration of signals for activation and inhibition. Annu. Rev. Immunol. 2013, 31, 227-258. [CrossRef]

2. Morvan, M.G.; Lanier, L.L. NK cells and cancer: You can teach innate cells new tricks. Nat. Rev. Cancer 2016, 16, 7-19. [CrossRef] [PubMed]

3. Carlsten, M.; Jaras, M. Natural Killer Cells in Myeloid Malignancies: Immune Surveillance, NK Cell Dysfunction, and Pharmacological Opportunities to Bolster the Endogenous NK Cells. Front. Immunol. 2019, 10, 2357. [CrossRef] [PubMed]

4. Guillerey, C.; Huntington, N.D.; Smyth, M.J. Targeting natural killer cells in cancer immunotherapy. Nat. Immunol. 2016, 17, 1025-1036. [CrossRef]

5. Lopez-Soto, A.; Gonzalez, S.; Smyth, M.J.; Galluzzi, L. Control of Metastasis by NK Cells. Cancer Cell 2017, 32, 135-154. [CrossRef] [PubMed]

6. Shimasaki, N.; Jain, A.; Campana, D. NK cells for cancer immunotherapy. Nat. Rev. Drug Discov. 2020, 19, 200-218. [CrossRef]

7. Beurel, E.; Michalek, S.M.; Jope, R.S. Innate and adaptive immune responses regulated by glycogen synthase kinase-3 (GSK3). Trends Immunol. 2010, 31, 24-31. [CrossRef] [PubMed]

8. Jope, R.S.; Johnson, G.V. The glamour and gloom of glycogen synthase kinase-3. Trends Biochem. Sci. 2004, 29, 95-102. [CrossRef]

9. Augello, G.; Emma, M.R.; Cusimano, A.; Azzolina, A.; Montalto, G.; McCubrey, J.A.; Cervello, M. The Role of GSK-3 in Cancer Immunotherapy: GSK-3 Inhibitors as a New Frontier in Cancer Treatment. Cells 2020, 9, 1427. [CrossRef]

10. Pandey, M.K.; DeGrado, T.R. Glycogen Synthase Kinase-3 (GSK-3)-Targeted Therapy and Imaging. Theranostics 2016, 6, 571-593. [CrossRef]

11. Woodgett, J.R. Molecular cloning and expression of glycogen synthase kinase-3/factor A. EMBO J. 1990, 9, 2431-2438. [CrossRef]

12. Doble, B.W.; Patel, S.; Wood, G.A.; Kockeritz, L.K.; Woodgett, J.R. Functional redundancy of GSK-3alpha and GSK-3beta in Wnt/beta-catenin signaling shown by using an allelic series of embryonic stem cell lines. Dev. Cell 2007, 12, 957-971. [CrossRef] [PubMed]

13. Hoeflich, K.P.; Luo, J.; Rubie, E.A.; Tsao, M.S.; Jin, O.; Woodgett, J.R. Requirement for glycogen synthase kinase-3beta in cell survival and NF-kappaB activation. Nature 2000, 406, 86-90. [CrossRef] [PubMed]

14. Kerkela, R.; Kockeritz, L.; Macaulay, K.; Zhou, J.; Doble, B.W.; Beahm, C.; Greytak, S.; Woulfe, K.; Trivedi, C.M.; Woodgett, J.R.; et al. Deletion of GSK-3beta in mice leads to hypertrophic cardiomyopathy secondary to cardiomyoblast hyperproliferation. $J$. Clin. Investig. 2008, 118, 3609-3618. [CrossRef] [PubMed]

15. MacAulay, K.; Doble, B.W.; Patel, S.; Hansotia, T.; Sinclair, E.M.; Drucker, D.J.; Nagy, A.; Woodgett, J.R. Glycogen synthase kinase 3alpha-specific regulation of murine hepatic glycogen metabolism. Cell Metab. 2007, 6, 329-337. [CrossRef]

16. Phiel, C.J.; Wilson, C.A.; Lee, V.M.; Klein, P.S. GSK-3alpha regulates production of Alzheimer's disease amyloid-beta peptides. Nature 2003, 423, 435-439. [CrossRef]

17. Linding, R.; Jensen, L.J.; Ostheimer, G.J.; van Vugt, M.A.; Jorgensen, C.; Miron, I.M.; Diella, F.; Colwill, K.; Taylor, L.; Elder, K.; et al. Systematic discovery of in vivo phosphorylation networks. Cell 2007, 129, 1415-1426. [CrossRef]

18. Sutherland, C. What Are the bona fide GSK3 Substrates? Int. J. Alzheimers Dis. 2011, 2011, 505607. [CrossRef]

19. Patel, P.; Woodgett, J.R. Glycogen Synthase Kinase 3: A Kinase for All Pathways? Curr. Top. Dev. Biol. 2017, 123, 277-302. [CrossRef]

20. Beurel, E.; Grieco, S.F.; Jope, R.S. Glycogen synthase kinase-3 (GSK3): Regulation, actions, and diseases. Pharmacol. Ther. 2015, 148, 114-131. [CrossRef]

21. McCubrey, J.A.; Steelman, L.S.; Bertrand, F.E.; Davis, N.M.; Abrams, S.L.; Montalto, G.; D'Assoro, A.B.; Libra, M.; Nicoletti, F.; Maestro, R.; et al. Multifaceted roles of GSK-3 and Wnt/beta-catenin in hematopoiesis and leukemogenesis: Opportunities for therapeutic intervention. Leukemia 2014, 28, 15-33. [CrossRef]

22. Luo, J. Glycogen synthase kinase 3beta (GSK3beta) in tumorigenesis and cancer chemotherapy. Cancer Lett. 2009, 273, 194-200. [CrossRef]

23. Wang, Z.; Smith, K.S.; Murphy, M.; Piloto, O.; Somervaille, T.C.; Cleary, M.L. Glycogen synthase kinase 3 in MLL leukaemia maintenance and targeted therapy. Nature 2008, 455, 1205-1209. [CrossRef]

24. Wu, X.; Stenson, M.; Abeykoon, J.; Nowakowski, K.; Zhang, L.; Lawson, J.; Wellik, L.; Li, Y.; Krull, J.; Wenzl, K.; et al. Targeting glycogen synthase kinase 3 for therapeutic benefit in lymphoma. Blood 2019, 134, 363-373. [CrossRef] [PubMed] 
25. Gunn, W.G.; Krause, U.; Lee, N.; Gregory, C.A. Pharmaceutical inhibition of glycogen synthetase kinase-3beta reduces multiple myeloma-induced bone disease in a novel murine plasmacytoma xenograft model. Blood 2011, 117, 1641-1651. [CrossRef] [PubMed]

26. Kwon, H.J.; Kwon, S.J.; Lee, H.; Park, H.R.; Choi, G.E.; Kang, S.W.; Kwon, S.W.; Kim, N.; Lee, S.Y.; Ryu, S.; et al. NK cell function triggered by multiple activating receptors is negatively regulated by glycogen synthase kinase-3beta. Cell Signal. 2015, 27, 1731-1741. [CrossRef]

27. Parameswaran, R.; Ramakrishnan, P.; Moreton, S.A.; Xia, Z.; Hou, Y.; Lee, D.A.; Gupta, K.; deLima, M.; Beck, R.C.; Wald, D.N. Repression of GSK3 restores NK cell cytotoxicity in AML patients. Nat. Commun. 2016, 7, 11154. [CrossRef] [PubMed]

28. Fionda, C.; Malgarini, G.; Soriani, A.; Zingoni, A.; Cecere, F.; Iannitto, M.L.; Ricciardi, M.R.; Federico, V.; Petrucci, M.T.; Santoni, A.; et al. Inhibition of glycogen synthase kinase-3 increases NKG2D ligand MICA expression and sensitivity to NK cell-mediated cytotoxicity in multiple myeloma cells: Role of STAT3. J. Immunol. 2013, 190, 6662-6672. [CrossRef]

29. Kim, N.; Lee, H.H.; Lee, H.J.; Choi, W.S.; Lee, J.; Kim, H.S. Natural killer cells as a promising therapeutic target for cancer immunotherapy. Arch. Pharm. Res. 2019, 42, 591-606. [CrossRef]

30. Raulet, D.H.; Gasser, S.; Gowen, B.G.; Deng, W.; Jung, H. Regulation of ligands for the NKG2D activating receptor. Annu. Rev. Immunol. 2013, 31, 413-441. [CrossRef]

31. Brandt, C.S.; Baratin, M.; Yi, E.C.; Kennedy, J.; Gao, Z.; Fox, B.; Haldeman, B.; Ostrander, C.D.; Kaifu, T.; Chabannon, C.; et al. The B7 family member B7-H6 is a tumor cell ligand for the activating natural killer cell receptor NKp30 in humans. J. Exp. Med. 2009, 206, 1495-1503. [CrossRef] [PubMed]

32. Fiegler, N.; Textor, S.; Arnold, A.; Rolle, A.; Oehme, I.; Breuhahn, K.; Moldenhauer, G.; Witzens-Harig, M.; Cerwenka, A. Downregulation of the activating NKp30 ligand B7-H6 by HDAC inhibitors impairs tumor cell recognition by NK cells. Blood 2013, 122, 684-693. [CrossRef]

33. Yuan, H.; Wang, Z.; Gao, C.; Chen, W.; Huang, Q.; Yee, J.K.; Bhatia, R.; Chen, W. BCR-ABL gene expression is required for its mutations in a novel KCL-22 cell culture model for acquired resistance of chronic myelogenous leukemia. J. Biol. Chem. 2010, 285, 5085-5096. [CrossRef]

34. Kwon, H.J.; Choi, G.E.; Ryu, S.; Kwon, S.J.; Kim, S.C.; Booth, C.; Nichols, K.E.; Kim, H.S. Stepwise phosphorylation of p65 promotes NF-kappaB activation and NK cell responses during target cell recognition. Nat. Commun. 2016, 7, 11686. [CrossRef]

35. Jun, E.; Song, A.Y.; Choi, J.W.; Lee, H.H.; Kim, M.Y.; Ko, D.H.; Kang, H.J.; Kim, S.W.; Bryceson, Y.; Kim, S.C.; et al. Progressive Impairment of NK Cell Cytotoxic Degranulation Is Associated With TGF-beta1 Deregulation and Disease Progression in Pancreatic Cancer. Front. Immunol. 2019, 10, 1354. [CrossRef]

36. Hyun, Y.M.; Seo, S.U.; Choi, W.S.; Kwon, H.J.; Kim, D.Y.; Jeong, S.; Kang, G.Y.; Yi, E.; Kim, M.; Ryu, H.J.; et al. Endogenous DEL-1 restrains melanoma lung metastasis by limiting myeloid cell-associated lung inflammation. Sci. Adv. 2020, 6, eabc4882. [CrossRef]

37. Kim, N.; Kim, M.Y.; Cho, Y.U.; Chen, W.; Lee, K.H.; Kim, H.S. PVR and ICAM-1 on Blast Crisis CML Stem and Progenitor Cells with TKI Resistance Confer Susceptibility to NK Cells. Cancers 2020, 12, 1923. [CrossRef] [PubMed]

38. Jang, H.D.; Noh, J.Y.; Shin, J.H.; Lin, J.J.; Lee, S.Y. PTEN regulation by the Akt/GSK-3beta axis during RANKL signaling. Bone 2013, 55, 126-131. [CrossRef]

39. Wang, Q.; Zhou, Y.; Wang, X.; Evers, B.M. Glycogen synthase kinase-3 is a negative regulator of extracellular signal-regulated kinase. Oncogene 2006, 25, 43-50. [CrossRef] [PubMed]

40. Raulet, D.H.; Marcus, A.; Coscoy, L. Dysregulated cellular functions and cell stress pathways provide critical cues for activating and targeting natural killer cells to transformed and infected cells. Immunol. Rev. 2017, 280, 93-101. [CrossRef]

41. Liu, X.V.; Ho, S.S.; Tan, J.J.; Kamran, N.; Gasser, S. Ras activation induces expression of Raet1 family NK receptor ligands. J. Immunol. 2012, 189, 1826-1834. [CrossRef]

42. Borchers, M.T.; Harris, N.L.; Wesselkamper, S.C.; Vitucci, M.; Cosman, D. NKG2D ligands are expressed on stressed human airway epithelial cells. Am. J. Physiol. Lung Cell. Mol. Physiol. 2006, 291, L222-L231. [CrossRef]

43. Kauffmann-Zeh, A.; Rodriguez-Viciana, P.; Ulrich, E.; Gilbert, C.; Coffer, P.; Downward, J.; Evan, G. Suppression of c-Myc-induced apoptosis by Ras signalling through PI(3)K and PKB. Nature 1997, 385, 544-548. [CrossRef]

44. Skorski, T.; Bellacosa, A.; Nieborowska-Skorska, M.; Majewski, M.; Martinez, R.; Choi, J.K.; Trotta, R.; Wlodarski, P.; Perrotti, D.; Chan, T.O.; et al. Transformation of hematopoietic cells by BCR/ABL requires activation of a PI-3k/Akt-dependent pathway. EMBO J. 1997, 16, 6151-6161. [CrossRef]

45. Nanbakhsh, A.; Pochon, C.; Mallavialle, A.; Amsellem, S.; Bourhis, J.H.; Chouaib, S. c-Myc regulates expression of NKG2D ligands ULBP1/2/3 in AML and modulates their susceptibility to NK-mediated lysis. Blood 2014, 123, 3585-3595. [CrossRef]

46. Sears, R.; Nuckolls, F.; Haura, E.; Taya, Y.; Tamai, K.; Nevins, J.R. Multiple Ras-dependent phosphorylation pathways regulate Myc protein stability. Genes Dev. 2000, 14, 2501-2514. [CrossRef]

47. Gregory, M.A.; Qi, Y.; Hann, S.R. Phosphorylation by glycogen synthase kinase-3 controls c-myc proteolysis and subnuclear localization. J. Biol. Chem. 2003, 278, 51606-51612. [CrossRef] [PubMed]

48. Doble, B.W.; Woodgett, J.R. GSK-3: Tricks of the trade for a multi-tasking kinase. J. Cell Sci. 2003, 116, 1175-1186. [CrossRef] [PubMed]

49. Force, T.; Woodgett, J.R. Unique and overlapping functions of GSK-3 isoforms in cell differentiation and proliferation and cardiovascular development. J. Biol. Chem. 2009, 284, 9643-9647. [CrossRef] [PubMed] 
50. Shi, P.; Yin, T.; Zhou, F.; Cui, P.; Gou, S.; Wang, C. Valproic acid sensitizes pancreatic cancer cells to natural killer cell-mediated lysis by upregulating MICA and MICB via the PI3K/Akt signaling pathway. BMC Cancer 2014, 14, 370. [CrossRef]

51. Xia, C.; He, Z.; Cai, Y.; Liang, S. Vorinostat upregulates MICA via the PI3K/Akt pathway to enhance the ability of natural killer cells to kill tumor cells. Eur. J. Pharmacol. 2020, 875, 173057. [CrossRef]

52. Cohen, P.; Frame, S. The renaissance of GSK3. Nat. Rev. Mol. Cell Biol. 2001, 2, 769-776. [CrossRef]

53. Felsher, D.W.; Bishop, J.M. Reversible tumorigenesis by MYC in hematopoietic lineages. Mol. Cell 1999, 4, 199-207. [CrossRef]

54. Vita, M.; Henriksson, M. The Myc oncoprotein as a therapeutic target for human cancer. Semin. Cancer Biol. 2006, 16, 318-330. [CrossRef]

55. Unni, A.M.; Bondar, T.; Medzhitov, R. Intrinsic sensor of oncogenic transformation induces a signal for innate immunosurveillance. Proc. Natl. Acad. Sci. USA 2008, 105, 1686-1691. [CrossRef]

56. Kazi, A.; Xiang, S.; Yang, H.; Delitto, D.; Trevino, J.; Jiang, R.H.Y.; Ayaz, M.; Lawrence, H.R.; Kennedy, P.; Sebti, S.M. GSK3 suppression upregulates beta-catenin and c-Myc to abrogate KRas-dependent tumors. Nat. Commun. 2018, 9, 5154. [CrossRef]

57. Textor, S.; Bossler, F.; Henrich, K.O.; Gartlgruber, M.; Pollmann, J.; Fiegler, N.; Arnold, A.; Westermann, F.; Waldburger, N.; Breuhahn, K.; et al. The proto-oncogene Myc drives expression of the NK cell-activating NKp30 ligand B7-H6 in tumor cells. Oncoimmunology 2016, 5, e1116674. [CrossRef]

58. Paczulla, A.M.; Rothfelder, K.; Raffel, S.; Konantz, M.; Steinbacher, J.; Wang, H.; Tandler, C.; Mbarga, M.; Schaefer, T.; Falcone, M.; et al. Absence of NKG2D ligands defines leukaemia stem cells and mediates their immune evasion. Nature 2019, 572, $254-259$. [CrossRef]

59. Sconocchia, G.; Lau, M.; Provenzano, M.; Rezvani, K.; Wongsena, W.; Fujiwara, H.; Hensel, N.; Melenhorst, J.; Li, J.; Ferrone, S.; et al. The antileukemia effect of HLA-matched NK and NK-T cells in chronic myelogenous leukemia involves NKG2D-target-cell interactions. Blood 2005, 106, 3666-3672. [CrossRef] [PubMed]

60. Banerji, V.; Frumm, S.M.; Ross, K.N.; Li, L.S.; Schinzel, A.C.; Hahn, C.K.; Kakoza, R.M.; Chow, K.T.; Ross, L.; Alexe, G.; et al. The intersection of genetic and chemical genomic screens identifies GSK-3alpha as a target in human acute myeloid leukemia. $J$. Clin. Investig. 2012, 122, 935-947. [CrossRef] [PubMed]

61. Ougolkov, A.V.; Bone, N.D.; Fernandez-Zapico, M.E.; Kay, N.E.; Billadeau, D.D. Inhibition of glycogen synthase kinase-3 activity leads to epigenetic silencing of nuclear factor kappaB target genes and induction of apoptosis in chronic lymphocytic leukemia $B$ cells. Blood 2007, 110, 735-742. [CrossRef]

62. Mirlashari, M.R.; Randen, I.; Kjeldsen-Kragh, J. Glycogen synthase kinase-3 (GSK-3) inhibition induces apoptosis in leukemic cells through mitochondria-dependent pathway. Leuk. Res. 2012, 36, 499-508. [CrossRef]

63. Wagner, F.F.; Benajiba, L.; Campbell, A.J.; Weiwer, M.; Sacher, J.R.; Gale, J.P.; Ross, L.; Puissant, A.; Alexe, G.; Conway, A.; et al. Exploiting an Asp-Glu "switch" in glycogen synthase kinase 3 to design paralog-selective inhibitors for use in acute myeloid leukemia. Sci. Transl. Med. 2018, 10, eaam8460. [CrossRef] [PubMed]

64. Guezguez, B.; Almakadi, M.; Benoit, Y.D.; Shapovalova, Z.; Rahmig, S.; Fiebig-Comyn, A.; Casado, F.L.; Tanasijevic, B.; Bresolin, S.; Masetti, R.; et al. GSK3 Deficiencies in Hematopoietic Stem Cells Initiate Pre-neoplastic State that Is Predictive of Clinical Outcomes of Human Acute Leukemia. Cancer Cell 2016, 29, 61-74. [CrossRef] [PubMed]

65. O'Hare, T.; Zabriskie, M.S.; Eiring, A.M.; Deininger, M.W. Pushing the limits of targeted therapy in chronic myeloid leukaemia. Nat. Rev. Cancer 2012, 12, 513-526. [CrossRef] [PubMed]

66. Soverini, S.; Mancini, M.; Bavaro, L.; Cavo, M.; Martinelli, G. Chronic myeloid leukemia: The paradigm of targeting oncogenic tyrosine kinase signaling and counteracting resistance for successful cancer therapy. Mol. Cancer 2018, 17, 49. [CrossRef] [PubMed] 